
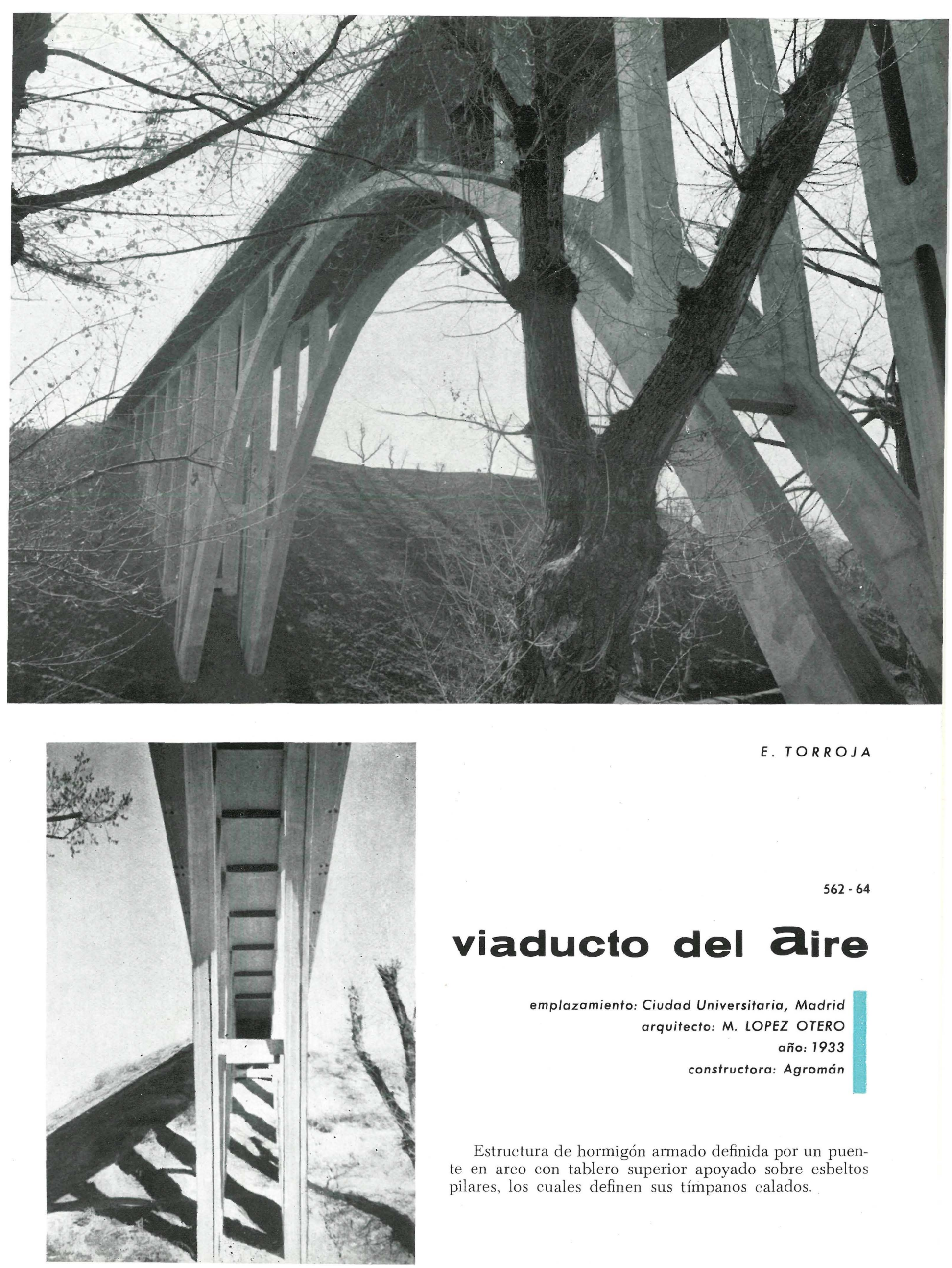

E. TORROJA

$562-64$

\title{
viaducto del aire
}

\author{
emplazamiento: Ciudad Universitaria, Madrid \\ arquitecto: M. LOPEZ OTERO \\ año: 1933 \\ constructora: Agromán
}

Estructura de hormigón armado definida por un puente en arco con tablero superior apoyado sobre esbeltos pilares, los cuales definen sus tímpanos calados. 


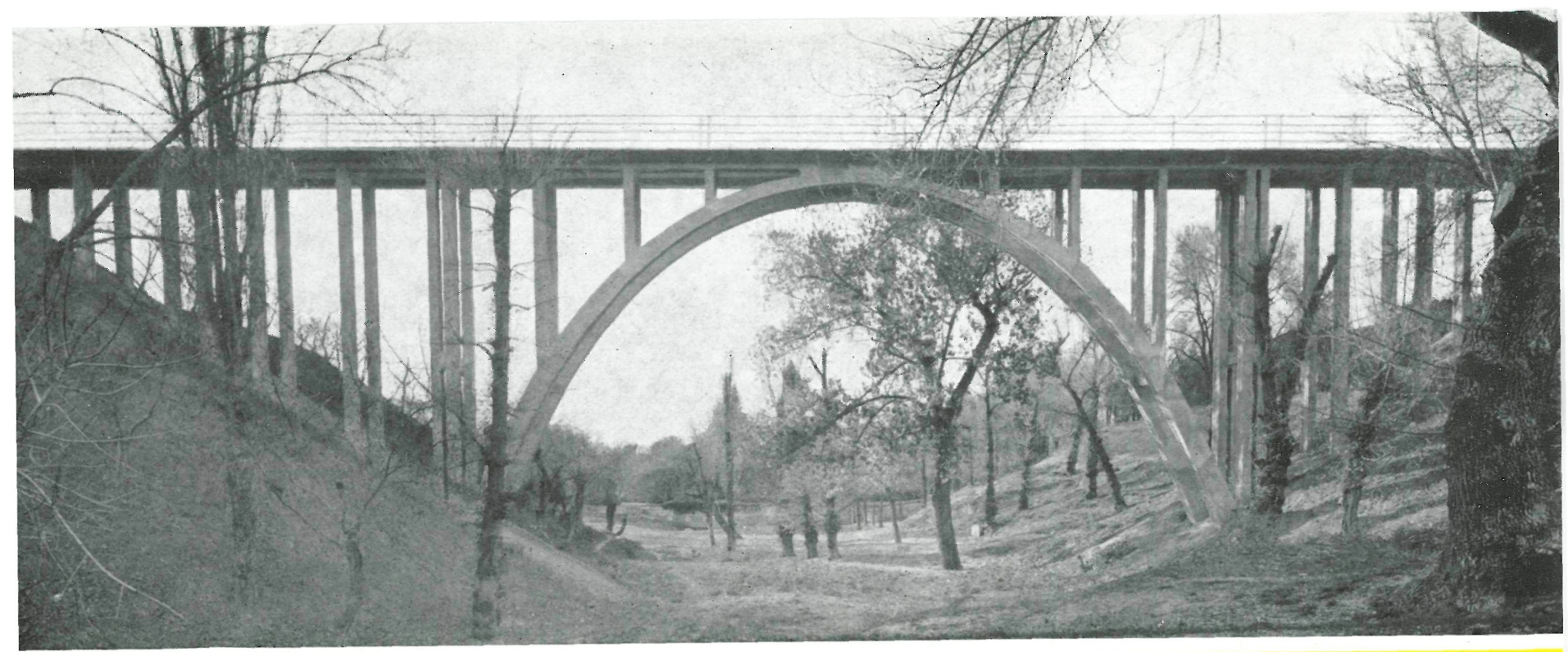

vista gemeral

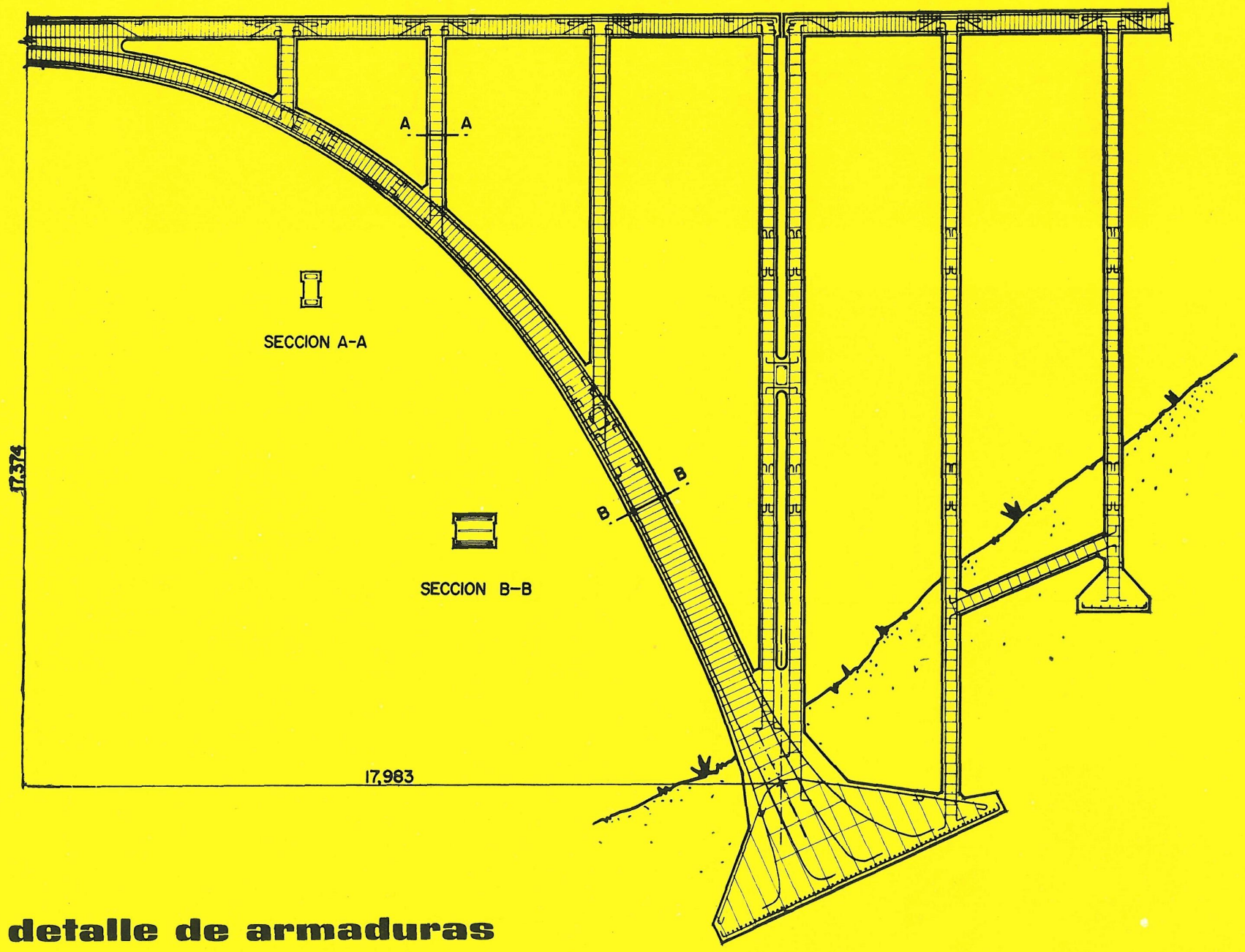




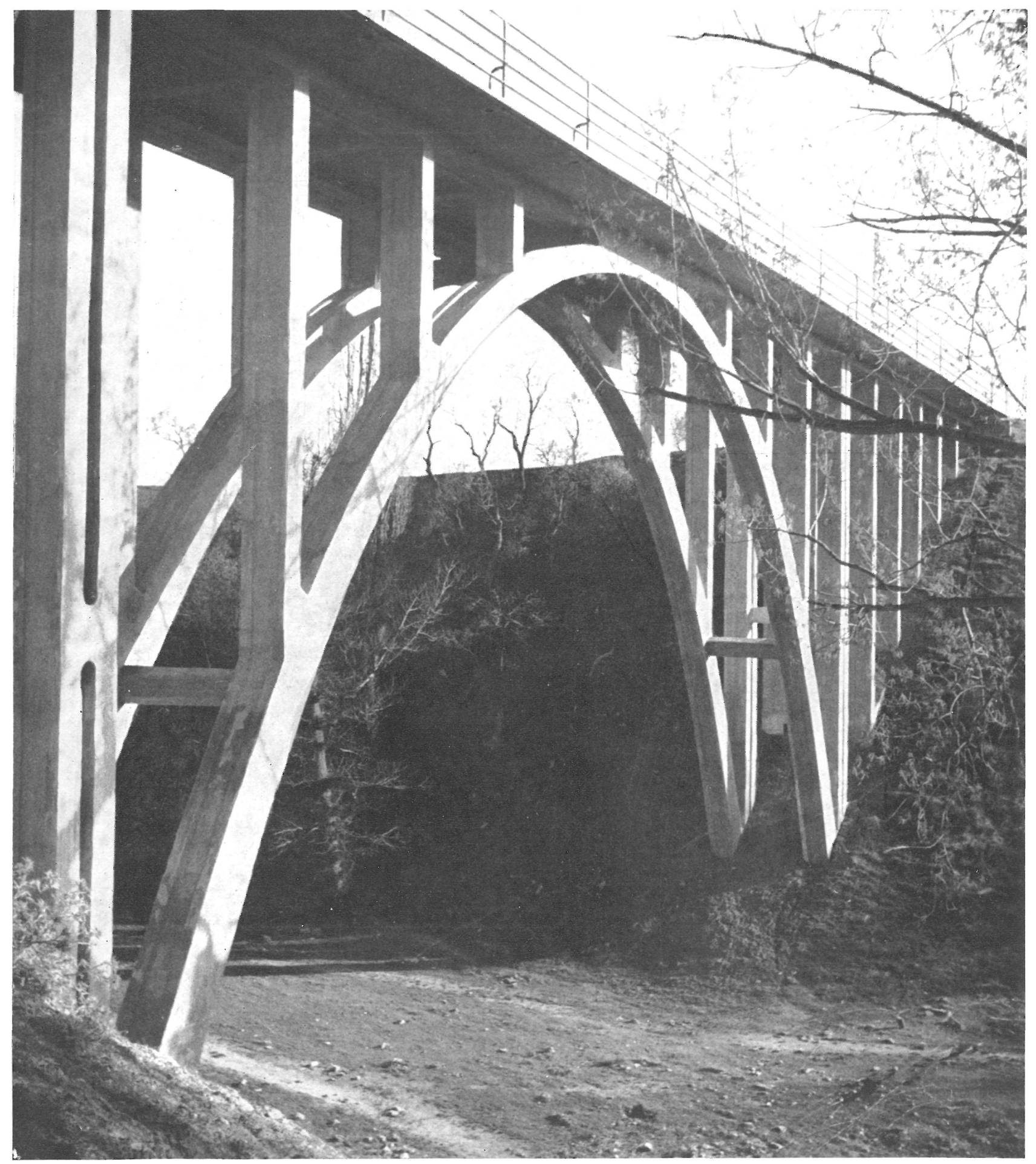

El arco propiamente dicho está definido por dos arcos gemelos, de 36 metros de luz, trabados en clave a través del tablero, en arranques y a una altura intermedia. La dilatación del tablero es absorbida por la flexibilidad de los pilares, gracias a su gran esbeltez.

Los vanos entre soportes no se proyectaron iguales, sino ligeramente menores los de menor altura, con objeto de compensar el efecto óptico de sus proporciones.

El arco fue calculado por aplicación gráfica del método de la elipse central de inercia. 


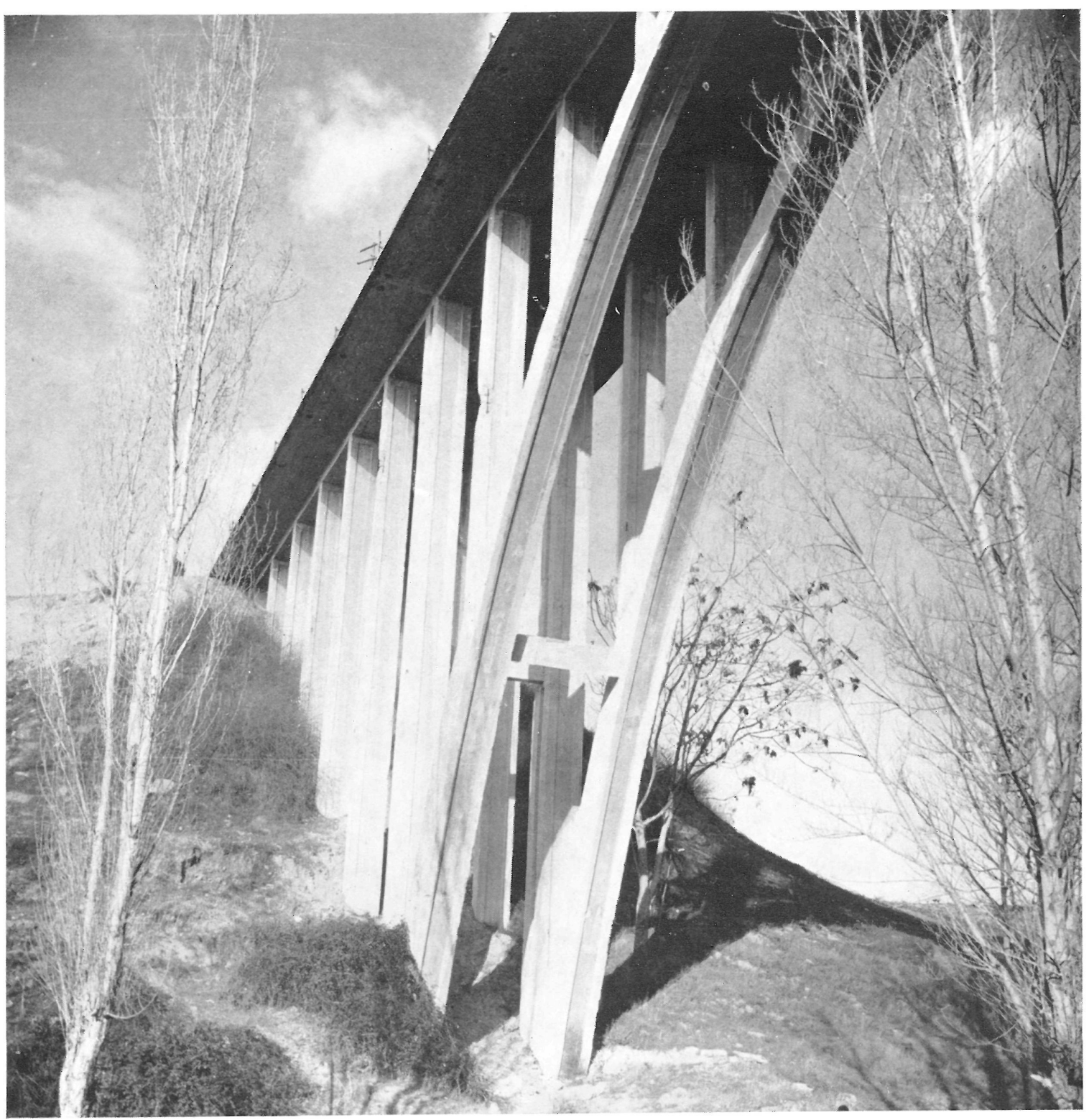

La solución estructural del Viaducto del Aire constituye un claro ejemplo de las posibilidades técnicas y plásticas que pueden obtenerse con el empleo de elementos longitudinales de gran esbeltez, propios de una estética lineal y geométrica. 